\title{
Теоретические и методические вопросы рекреационного районирования регионов России
}

\author{
Т. М. Худякова, О.А. Крутских, А. С. Рязанцев \\ Воронежский государственный педагогический университет, \\ Российская Федерация \\ (394043, г. Воронеж, ул. Ленина, 86)
}

\begin{abstract}
Аннотация: Цель - рассмотреть теоретические и методические вопросы рекреационного районирования регионов России для решения задач развития внутреннего туризма страны.

Maтериаль $u$ методыl. Информационной базой послужили теоретико-методологические работы географов и экономистов по вопросам рекреационного районирования регионов России, а также материалы национального туристского рейтинга. Предлагается выявить пути развития туристско-рекреационной деятельности в регионах на современном этапе на основе рациональной территориальной организации туризма и отдыха при использовании метода экономического районирования. Процесс экономического районирования в работе рассматривается как прогрессивный метод крупномасштабного экономико-географического анализа. Он позволяет раскрыть особенности функционирования туристско-рекреационных систем регионов, создавая основу для различных видов территориального управления.

Результаты и обсуждение. Туристско-рекреационная деятельность стала доходной отраслью нашего государства и имеет большие перспективы для дальнейшего развития в связи с многообразием туристских ресурсов на обширных пространствах России. Рекреационные потребности населения превращаются в важный социально-экономический фактор развития внутреннего туризма. Каждый регион, субъект РФ, обладает определенным сочетанием туристских ресурсов и имеет предпосылки для создания уникальных турпродуктов. Особую значимость развитие внутреннего туризма приобретает в связи с эпидемиологическими процессами и создавшейся геополитической ситуацией в современном мире. Однако решение вставших задач по усилению развития внутреннего туризма затруднено в связи с недостаточной транспортной обслуженностью ряда регионов и слабым развитием объектов туристской инфраструктуры.

Заключение. Изучение рекреационного районообразования приобретает особую значимость на современном этапе. Всесторонний анализ факторов и условий формирования туризма и отдыха позволяет определить сбалансированную, пропорциональную структуру рекреационного комплекса региона.
\end{abstract}

Ключевые слова: теоретические и методические вопросы рекреационного районирования, туристскорекреационная деятельность, рекреационное районирование, регионы России, специализация, комплексность, районообразующий центр, таксономические единицы рекреационного районирования.

Для цитирования: Худякова Т. М., Крутских О.А., Рязанцев А.С. Теоретические и методические вопросы рекреационного районирования регионов России // Вестник Воронежского государственного университета. Серия: География. Геоэкология, 2021, № 2, с. 55-60. DOI: https://oi.org/10.17308/ geo.2021.2/3448

\section{ВВЕДЕНИЕ}

Туристско-рекреационная деятельность занимает все более важное место в хозяйстве регионов России. Она стала доходной отраслью экономики страны и имеет большие перспективы для даль-

(C) Худякова Т.М., Крутских О.А., Рязанцев А.С., 2021

$\triangle$ Рязанцев Александр Сергеевич, e-mail: ekgeo.vspu@yandex.ru нейшего развития. Рекреационные потребности населения превращаются в важный социальноэкономический фактор развития внутреннего туризма России. Актуальность развития внутреннего туризма приобретает особую значимость в связи с эпидемиологическими процессами и создавшейся 
геополитической ситуацией в современном мире. Каждый регион (субъект) Российской Федерации обладает туристскими ресурсами и имеет предпосылки для создания турпродуктов. Национальный туристский рейтинг, проведенный в 2019 году, показал привлекательность и популярность регионов России для отечественных и зарубежных туристов.

\section{МАТЕРИАЛЫ И МЕТОДЫ}

Решение вставших задач по усилению развития внутреннего туризма в России в настоящее время может осуществляться на основе рациональной территориальной организации туризма и отдыха при использовании метода экономического районирования. Процесс экономического районирования в работе рассматривается как прогрессивный метод крупномасштабного экономико-географического анализа, позволяющий познать особенности формирования туристско-рекреационного комплекса региона. Основная цель районирования - определение оптимальных границ рекреационных районов, формирующихся в результате территориально разделения труда для повышения эффективности туристской отрасли. В отечественной экономико-географической науке накопился опыт использования этого метода. Экономическое районирование позволяет выделить сформировавшиеся организованные пространственные системы, создавая основу для различных видов территориального управления. На всех этапах хозяйственного развития нашего государства решались сложные отраслевые и межотраслевые проблемы формирования производственно-территориальных систем.

Территориальная организация туризма и отдыха в регионе на основе метода экономического районирования - это процесс установления рациональной структуры и связей при использовании социально-экономических, демографических, эколого-экономических и технико-экономических расчетов. Районирование территории основывается на анализе ресурсного потенциала (природных туристских ресурсов, культурно-исторических туристских ресурсов), изучения объектов туристкой инфраструктуры, а также определении районообразующих центров и пунктов туристской отрасли.

Одним из важных этапов исследования является учет природных туристских ресурсов региона. Географами Воронежского госуниверситета предложена методика расчетов туристских природных ресурсов и выделение рекреационных районов различного ранга в условиях лесостепной и степной зон Центрального Черноземья: округ, район, подрайон. Опираясь на особенности ландшафтной структуры территории Центрального Черноземья, они обосновывают сетку рекреационных таксонов [7].

Вопросы рекреационного районирования получили развитие в 70-80-е годы прошлого столетия. На этом этапе исследователи туристской отрасли обратили внимание на значимость регионального изучения для решения задач ее размещения и управления. Особо следует выделить работу Н.С. Мироненко и И.Т. Твердохлебова «Рекреационная география», в которой авторы глубоко обосновали теоретико-методологические и методические вопросы рекреационного районирования [4].

Крупный вклад в постсоветский период в разработку теоретических и методических вопросов туристского районирования внес А. И. Зырянов [1]. Он обосновал таксономические единицы туристского районирования: туристское местечко, туристское место, туристский центр и т.д. [3]. Принципы выделения туристских районов основаны на учете как физико-географических, так и административно-территориальных границ [2]. Его подход базируется на выявлении роли ландшафтных рубежей контрастности в формировании социально-экономической структуры регионов. Учет ландшафтного разнообразия позволяет совершенствовать территориальную организацию туристской деятельности и природопользования Пермского края [1].

\section{РЕЗУЛЬТАТЫ И ОБСУЖДЕНИЕ}

На современном этапе туристско-рекреационной деятельности необходим учет подходов в связи с появлением новых факторов развития и размещения отрасли туризма и отдыха. Так как в статье поставлена задача использовать теорию экономического районирования для анализа туристско-рекреационной деятельности в регионах, субъектах РФ, необходимо руководствоваться законодательными актами правительства. Подчеркнем значение Федерального закона ФЗ № 131 от 6 октября 2003 года «Об общих принципах организации местного самоуправления в Российской Федерации» [5]. Важным звеном в управлении территорией являются муниципальные районы. Расширение полномочий муниципальных образований позволяет увеличить доходы от туристской отрасли и пополнить местный бюджет.

Теоретико-методологической основой рекреационного районирования региона является системно-структурный подход, при использовании которого вычленяется из общественной системы региона туристско-рекреационный комплекс. Проведение всестороннего анализа многообраз- 
Иерархическая структура рекреационных районов субъекта Российской Федерации

[Table. Hierarchical structure of recreational areas of the region of the Russian Federation]

\begin{tabular}{|c|l|l|}
\hline \multicolumn{1}{|c|}{\begin{tabular}{|c|} 
Таксономический ранг / \\
Тахопотіс rank
\end{tabular}} & \multicolumn{1}{|c|}{$\begin{array}{c}\text { Административный состав рекреационных районов / } \\
\text { Administrative structure of recreational areas }\end{array}$} \\
\hline I & $\begin{array}{l}\text { Областной (краевой, } \\
\text { республиканский) макрорайон }\end{array}$ & $\begin{array}{l}\text { Рекреационный район в границах субъекта РФ (область, } \\
\text { край, республика) }\end{array}$ \\
\hline II & $\begin{array}{l}\text { Внутриобластной } \\
\text { (внутрикраевой, } \\
\text { внутриреспубликанский) } \\
\text { мезорайон }\end{array}$ & $\begin{array}{l}\text { Внутриобластной (внутрикраевой, внутриреспубликанский) } \\
\text { рекреационный подрайон, включающий группу } \\
\text { муниципальных районов }\end{array}$ \\
\hline III & Локальный, микрорайон & $\begin{array}{l}\text { Рекреационный микрорайон, включающий один или два } \\
\text { муниципальных района }\end{array}$ \\
\hline
\end{tabular}

ных связей туристских объектов позволяет выявить состав комплекса.

Рекреационное районирование - отраслевое районирование, оно является неотъемлемой частью интегрального экономического районирования. В то же время отраслевое районирование имеет самостоятельное научное и практическое значение. Отраслевые районы, как и интегральные, являются следствием территориального разделения труда.

Важный этап исследования - определение условий и факторов территориальной организации рекреационной отрасли. К числу основных факторов относятся: потребности населения страны в рекреационных услугах; углубление территориального разделения труда в сфере туризма и отдыха и как его следствие рекреационная специализация территории. Важными факторами являются также природные и культурно-исторические туристские ресурсы; экономико-географическое положение рекреационного района и его обеспеченность различными видами транспорта; административно-территориальное деление и организационно-управленческая структура региона [6].

Принимая во внимание действие указанных районообразующих факторов при выделении рекреационных районов, следует исходить из следующих принципов:

1) экономический принцип, т.е. учет рекреационной специализации района в предоставлении услуг рекреантам и создание турпродукта;

2) комплексность развития и размещения туристских объектов (рекреационных предприятий, предприятий и учреждений туристской инфраструктуры) для достижения пропорционального и сбалансированного развития и повышения качества обслуживания рекреантов;

3) учет сложившейся организационно-управлен- ческой структуры регионов, поскольку муниципальный район в современных условиях хозяйствования является важным звеном самоуправления;

4) выявление районообразующих центров и пунктов туризма и отдыха, выполняющих важную роль в организации обслуживания рекреантов;

5) перспективность развития туристкой отрасли на основе включения в рекреационный процесс новых неиспользованных до настоящего времени туристских ресурсов [8].

Исходя из этого, определим понятие «рекреационный район» как специализированную часть туристско-рекреационного пространства, обеспечиваюшую создание турпродукта для удовлетворения потребностей рекреантов. Районы выделяются в территориальном разделении труда рекреационной специализацией, наличием крупных туристских дестинаций, уровнем освоенности ресурсов территории, наличием объектов туристской инфраструктуры.

Туристско-рекреационное пространство регионов России неоднородно и имеет иерархическую структуру. Иерархия таксономических единиц регионов России включает следующие уровни: областной рекреационный макрорайон в границах субъекта Российской Федерации (область, край, республика); мезорайон или внутриобластной (внутрикраевой, внутриреспубликанский) и микрорайон или локальный рекреационный район (таблица).

На каждом иерархическом уровне выполняются определенные функции туристскими объектами по обслуживанию рекреантов. Поэтому рекреационное облуживание туристов основывается на учете иерархической структуры районов. Взаимосвязанность туристских объектов в процессе обслуживания рекреантов приводит к формированию пространственных сочетаний учреждений, предприятий, opганизаций и служб в населенных пунктах. Функции, выполняемые объектами, определяют роль и значи- 
мость населенного пункта в рекреационной системе как районообразующего центра.

Иерархия территориальных рекреационных образований отражает сложившуюся пространственную структуру рекреационного процесса. Отметим характерные признаки районов каждого уровня.

Областной (республиканский, краевой) рекреационный район выделяется в территориальном разделении труда РФ четкой рекреационной специализацией, наличием комплекса предприятий и служб производственной инфраструктуры, также районообразующей ролью главного центра области (края, республики). Администрацией области (края, республики) в соответствующих ее подразделениях разрабатываются концепция формирования и стратегия развития внутреннего туризма данной территории.

Внутриобластной (внутриреспубликанский, внутрикраевой) рекреационный район представляет собой группу муниципальных районов, характеризующихся определенным уровнем развития туристкой отрасли на основе рационального использования туристских ресурсов и инфраструктуры. Районообразующим центром является наиболее крупный населенный пункт одного из муниципальных районов данной территории, обладающий достаточной материально-технической базой для организации обслуживания туристов.

Локальный (микрорайон) рекреационный район представляет собой территорию одного или двух муниципальных районов. Его специализация характеризуется более узким набором видов туризма. Локальные районы имеют ограниченный набор вспомогательных и обслуживающих отраслей. Главная их роль - сохранить на микроуровне своеобразие уникальных туристских ресурсов, неиспользуемых в настоящее время.

\section{ЗАКЛЮЧЕНИЕ}

Внутренний туризм приобретает особую значимость на современном этапе развития нашего государства. Поэтому требуется определить роль регионов страны в создании турпродуктов на основе рационального использования туристского потенциала каждой территории. Эту задачу необходимо решать на основе метода экономического районирования, разработанного в отечественной экономико-географической науке. Всесторонний анализ факторов и условий территории позволяет определить сбалансированную, пропорциональную структуру рекреационного комплекса региона и выявить границы рекреационных районов. Рекреационные районы представляют собой упорядоченные пространственные системы и служат основой территориального управления туристской отраслью. Основными признаками различного ранга рекреационных районов считаем показатели: специализацию на различных видах туристской деятельности, комплексность туристских объектов, представляющих услуги рекреантам и наличие районообразующего центра.

\section{СПИСОК ЛИТЕРАТУРЫ}

1. Зырянов А.И. География туризма: от теории к практике. Пермь: Издательский центр ПГНИУ, 2018. $415 \mathrm{c}$.

2. Зырянов А.И. Дробное районирование и площадное развитие туризма // Вестник Московского университета, Серия 5. География, 2018, № 5, с. 44-51.

3. Зырянов А.И. Систематизация туристских таксонов // Вестник Московского университета. Серия 5. География, 2014, №3, с. 16-22.

4. Мироненко Н.С., Твердохлебов И.Т. Рекреационная география. Москва: МГУ, 1981. 208 с.

5. Российская Федерация. Законы. Федеральный закон «Об общих принципах организации местного самоуправления в Российской Федерации» от 06.10.2003 N 131-Ф3.

6. Рязанцев А.С., Худякова Т.М. Территориальная структура туристско-рекреационного потенциала Воронежской области // Вестник Воронежского государственного университета. Серия: География. Геоэкология, 2019, №3, с. 86-91. DOI: https://doi.org/10.17308/ geo.2019.3/2330.

7. Федотов В.И., Федотов С.В. Туристско-рекреационные зоны и районы // Эколого-географический атлас-книга Воронежской области, 2013, с. 417-419.

8. Худякова, Т.М., Рязанцев А.С. Формирование туристско-рекреационного комплекса Воронежской области // Вестник Воронежского государственного университета. Серия: География. Геоэкология, 2017, №3, c. 113-119.

Конфликт интересов: Авторы декларируют отсутствие явных и потенциальных конфликтов интересов, связанных с публикацией настоящей статьи.

Поступила в редакциию 16.11.2020 Принята к публикациии 28.05.2021 


\title{
Theoretical and Methodological Issues of Recreational Zoning of Russian Regions
}

\author{
T. M. Khudyakova, O.A. Krutskikh, A. S. Ryazantsev ${ }^{\square}$ \\ Voronezh State Pedagogical University, Russian Federation \\ (86, Lenin St., Voronezh, 394043)
}

\begin{abstract}
Purpose: to consider the theoretical and methodological issues of recreational zoning of Russian regions for solving the problems of developing the country's domestic tourism. It makes it possible to reveal the peculiarities of the functioning of the tourist and recreational systems of the regions, creating the basis for various types of territorial administration.

Materials and methods. The information base was the theoretical and methodological works of geographers and economists on the recreational zoning of Russian regions, as well as materials from the national tourist rating. It is proposed to identify ways to develop tourist and recreational activities in the regions at the present stage on the basis of rational territorial organization of tourism and recreation using the method of economic zoning. The process of economic zoning is considered as a progressive method of large-scale economic and geographical analysis.

Results and discussion. Tourist and recreational activities have become a profitable branch of our country and have great prospects for further development due to the variety of tourist resources in the vast expanses of Russia. Recreational needs of the population are becoming an important socio-economic factor in the development of domestic tourism. Each region of the Russian Federation has a certain combination of tourist resources and has prerequisites for creating unique tourist products. The development of domestic tourism is particularly important due to epidemiological processes and the current geopolitical situation in the modern world. However, it is difficult to solve the problems that have arisen to strengthen the development of domestic tourism due to insufficient transport services in a number of regions and the weak development of tourist infrastructure.

Conclusions. The study of recreational district formation is of particular importance at the present stage. A comprehensive analysis of factors and conditions of the formation of tourism and recreation allows us to determine a balanced, proportional structure of the recreational complex of the region.
\end{abstract}

Key words: theoretical and methodological issues of recreational zoning, tourist and recreational activities, recreational zoning, regions of Russia, specialization, complexity, district-forming center, taxonomic units of recreational zoning.

For citation: Khudyakova T. M., Krutskikh O.A., Ryazantsev A. S. Theoretical and Methodological Issues of Recreational Zoning of Russian Regions. Vestnik Voronezskogo gosudarstvennogo universiteta. Seria: Geografia. Geoekologia, 2021, no. 2, pp. 55-60. (In Russ.). DOI: https://doi.org/10.17308/geo.2021.2/3448

\section{REFERENCES}

1. Zyryanov A.I. Geografiya turizma: ot teorii $\mathrm{k}$ praktike [Geography of tourism: from theory to practice]. Permian: Izdatel'skij centr PGNIU, 2018. 415 p. (In Russ.)

2. Zyryanov A.I. Drobnoe rajonirovanie i ploshchadnoe razvitie turizma [Fractional zoning and areal tourism development]. Vestnik Moskovskogo universiteta. Seriya 5. Geografiya, 2018, no. 5, pp. 44-51. (In Russ.)

3. Zyryanov A.I. Sistematizaciya turistskih taksonov [Systematization of tourist taxa]. Vestnik Moskovskogo universiteta. Seriya 5. Geografiya, 2014. no. 3, pp. 16-22. (In Russ.)
4. Mironenko N. S., Tverdohlebov I. T. Rekreacionnaya geografiya [Recreational geography]. Moscow, MGU, 1981. 208 p. (In Russ.)

5. Rossijskaya Federaciya. Zakony. Federal'nyj zakon «Ob obshchih principah organizacii mestnogo samoupravleniya v Rossijskoj Federacii» [Russian Federation. The laws. Federal Law "On General Principles of Organization of Local Self-Government in the Russian Federation"] ot 06.10.2003 N 131-FZ. (In Russ.)

6. Ryazancev A.S., Hudyakova T.M. Territorial'naya struktura turistsko-rekreacionnogo potenciala Voronezhskoj oblasti [Territorial structure of the tourist and recreational potential of the Voronezh region]. Vestnik Voronezhskogo

(C) Khudyakova T.M., Krutskikh O.A., Ryazantsev A. S., 2021

$\bowtie$ Alexandr S. Ryazantsev, e-mail: ekgeo.vspu@yandex.ru 
gosudarstvennogo universiteta. Seria Geografia. Geoekologia, 2019, no 3, pp. 86-91. (In Russ.) DOI: https://doi. org/10.17308/geo.2019.3/2330.

7. Fedotov V.I., Fedotov S.V. Turistsko-rekreacionnye zony $i$ rajony // Ekologo-geograficheskij atlas-kniga Voronezhskoj oblasti [Tourist and recreational zones and areas // Ecological and geographic atlas-book of the Voronezh region]. 2013, pp. 417-419. (In Russ.)

8. Hudyakova T.M., Ryazancev A.S. Formirovanie turistsko-rekreacionnogo kompleksa Voronezhskoj oblasti

\section{Худякова Тамара Михайловна}

доктор географических наук, профессор кафедры географии и туризма Воронежского государственного педагогического университета, г. Воронеж, Российская Федерация, ORCID: 0000-0001-5773-4871, e-mail: ekgeo.vspu@yandex.ru

Крутских Ольга Александровна

кандидат географических наук, доцент, заведующая кафедрой географии и туризма Воронежского государственного педагогического университета, г. Воронеж, Российская Федерация, ORCID: 0000-0002-3748-7567, e-mail: ekgeo.vspu@yandex.ru

\section{Рязанцев Александр Сергеевич}

ассистент кафедры географии и туризма Воронежского государственного педагогического университета, г. Воронеж, Российская Федерация, ORCID: 0000-00023647-3403, e-mail: ekgeo.vspu@yandex.ru
[Formation of the tourist and recreational complex of the Voronezh region]. Vestnik Voronezhskogo gosudarstvennogo universiteta. Seria Geografia. Geoekologia, 2017. no. 3, pp. 113-119. (In Russ.)

Conflict of interests: The authors declare no information of obvious and potential conflicts of interest related to the publication of this article.

Received: 16.11.2020 Accepted: 28.05.2021

Tamara M. Khudyakova

Dr. Sci. (Geogr.), Professor of Geography and Tourism Department, Voronezh State Pedagogical University, Voronezh, Russian Federation, ORCID: 0000-0001-5773-4871, e-mail: ekgeo.vspu@yandex.ru

Olga A. Krutskikh

Cand. Sci. (Geogr.), Associate Professor, the Head of the Department of Geography and Tourism, Voronezh State Pedagogical University, Voronezh, Russian Federation, ORCID: 0000-0002-3748-7567, e-mail: ekgeo.vspu@yandex.ru

Alexandr S. Ryazantsev

Assistant of Geography and Tourism department, Voronezh State Pedagogical University, Voronezh, Russian Federation, ORCID: 0000-0002-3647-3403, e-mail: ekgeo. vspu@yandex.ru 